\title{
Laparoscopic gastrectomy with regional lymph node dissection for upper gastric cancer
}

\author{
Shinya Tanimura ${ }^{1}$, Masayuki Higashino ${ }^{1}$, Yosuke Fukunaga $^{1}$, and Harushi Osugi ${ }^{2}$ \\ ${ }^{1}$ Department of Gastroenterological Surgery, Osaka City General Hospital, 2-13-22 Miyakojimahondori, Miyakojima-ku, Osaka 534-0021, \\ Japan \\ ${ }^{2}$ Department of Gastroenterological Surgery, Osaka City University School of Medicine, Osaka, Japan
}

\begin{abstract}
Recently, a minimally invasive operation for gastric malignancies has been developed, and this laparoscopic operation is seen as a technique that will raise quality of life for patients. Previously, we reported this technique, as well as the results of a distal gastrectomy with regional lymph node dissection using hand-assisted laparoscopic surgery (HALS) for gastric cancer located in the middle or lower third of the stomach. This paper describes total or proximal gastrectomy with regional lymph node dissection by HALS on 28 cases of gastric cancer located in the upper portion of the stomach. After the mobilization of stomach and lymph node dissection via HALS, an anastomosis of the esophagus was performed intracorporeally with a conventional circular stapling device (PCEEA), whereas jejunojejunostomy and jejunogastrostomy were carried out extracorporeally with a conventional hand-sewn procedure through a HALS wound. The operation time and the amount of blood loss in all the patients were considered to be satisfactory, and the average number of dissected lymph nodes per patient was similar to that in open surgery. The patients had minimal morbidity and quick recovery after their operation. This technique was thought to be not only less invasive, but also similarly curative compared with open gastrectomy.
\end{abstract}

Key words Hand-assisted laparoscopic surgery (HALS) · Intracorporeal anastomosis - Laparoscopic total gastrectomy · Laparoscopic proximal gastrectomy $\cdot$ Lymph node dissection

\section{Introduction}

Recently, a less invasive operation for gastric cancer has been developed. Previously we reported this technique, as well as the results of distal gastrectomy with regional lymph node dissection using hand-assisted laparoscopic surgery (HALS) for gastric cancer located in the middle or lower third of the stomach [1,2]. This paper describes

Offprint requests to: $\mathrm{S}$. Tanimura

Received: May 2, 2002 / Accepted: September 12, 2002 the procedure, and reports the advantages of laparoscopic surgery by HALS for gastric cancer located in the upper portion of the stomach.

\section{Patients and operational methods}

Between March 1998 and March 2002, we had 170 cases of laparoscopic distal gastrectomy with regional lymph node dissection for gastric cancer located in the middle or lower third of the stomach. Of these, 104 patients were operated on by HALS and 66 by a totally laparoscopic procedure without HALS. Here, we report on laparoscopic resection by HALS for 28 patients with upper gastric carcinoma between March 1999 and March 2002. All the lesions for which endoscopic mucosal resection or partial gastrectomy were not indicated were thought to be limited to submucosa deep within the tumor, where no evidence of lymph node metastases had been found in preoperative examinations $(\mathrm{cT} 1 \mathrm{cN} 0)$ (Table 1). The patients were divided into two groups according to the following criteria: (1) 16 patients (average age 61.4 years; range $40-84$ years; male-female ratio 11:5) whose lesions were spread in both the upper and middle thirds of the stomach (UM cases) were given total gastrectomy with D2 dissection followed by Roux-en-Y reconstruction; (2) 12 patients (average age 67.6 years; range $48-83$ years; male-female ratio 7:5) whose lesions were limited to the upper third of the stomach ( $U$ cases) were given proximal gastrectomy with D1 dissection followed by esophagogastrostomy, or D2 dissection followed by jejunal interposition. As a general rule, D1 dissection was performed for lesions where the invasion of the submucosa was slight (sm1), while D2 dissection was used for lesions which had massively invaded the submucosa ( $\mathrm{sm} 2)$.

The surgeon's left hand was inserted into the peritoneal cavity thorough a transverse skin incision about 
Table 1. Indications of upper gastric cancer

\begin{tabular}{ll}
\hline Procedure & \multicolumn{1}{c}{ Indications } \\
\hline Endoscopic mucosal resection & $\begin{array}{c}\text { Differentiated mucosal cancer less than } 2 \mathrm{~cm} \\
\text { without ulceration } \\
\text { cT1cN0, not limited by histological type }\end{array}$ \\
$\begin{array}{l}\text { Laparoscopic gastrectomy } \\
\text { Open gastrectomy }\end{array}$ & Over cT2 or cN1, not limited by histological type
\end{tabular}

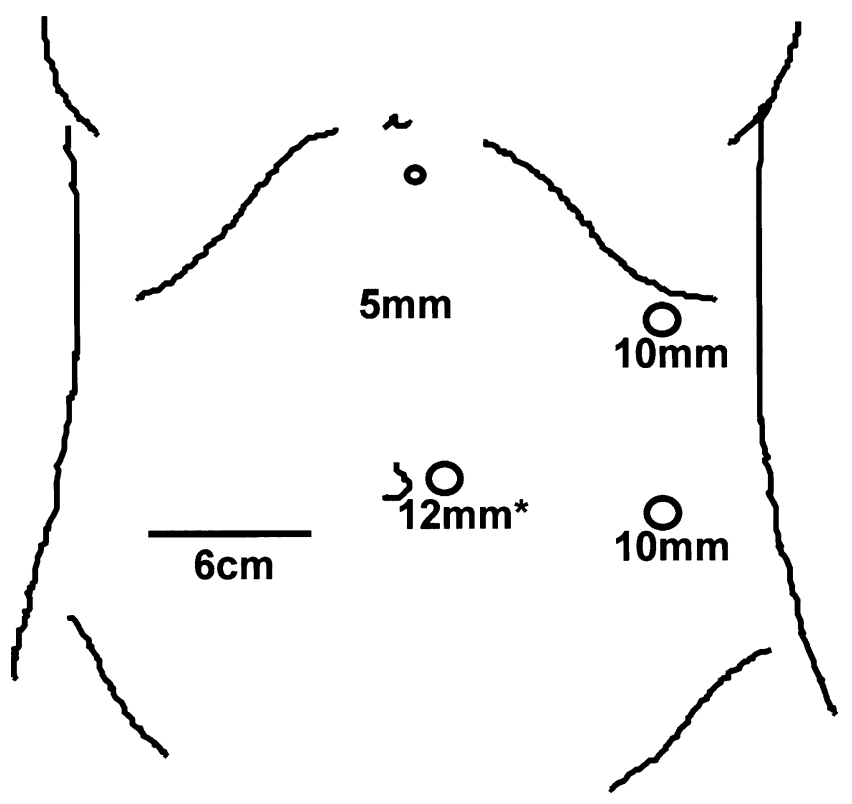

Fig. 1. Trocar placement and skin incision for hand-assisted laparoscopic surgery (HALS). *The $12-\mathrm{mm}$ port adjacent to the navel is enlarged to 3 or $4 \mathrm{~cm}$ in order to insert the body of the PCEEA into the peritoneal cavity at reconstruction

$6 \mathrm{~cm}$ long in the right lower quadrant. A lap disk (Hakko Shoji, Tokyo, Japan) was fitted to the wound to keep the pneumoperitoneal pressure at $10 \mathrm{mmHg}$, and then four trocars, $5-12 \mathrm{~mm}$ in diameter, were put in position (Fig. 1). As a general rule, stomach ablation and lymph node dissection were performed in the same manner as for conventional open surgery. All lymph nodes belonging to groups 1 and 2, defined according to the Japanese classification of gastric carcinomas [3], were dissected in D2 cases. For this procedure, a relatively sharp ablation technique was performed using ultrasonic coagulation shears (Ultrashears, United States Surgical Corporation, USSC, Norwalk, CT, USA). We did not perform blunt dissection with the left hand inserted into the peritoneal cavity, and this helped to develop an appropriate operating field. A laparoscopic image around the celiac artery and the splenic artery after lymph node dissection is shown in Fig. 2.

Transection of the abdominal esophagus was performed after grasping it with a pursestring device (PSD, Ethicon, Cincinnati, OH, USA), or with a hand-sewn cigarette suture of the esophageal stump, followed by

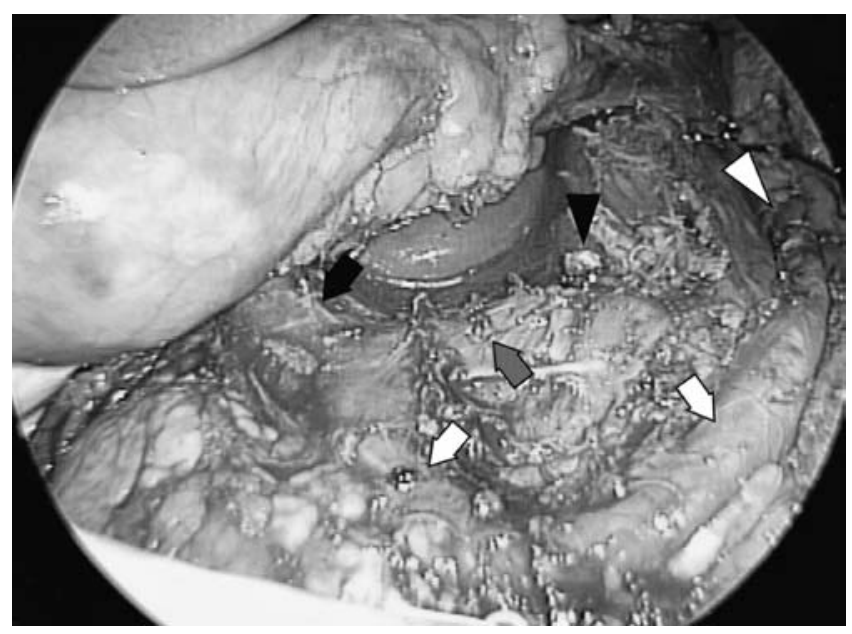

Fig. 2. Laparoscopic image around the celiac artery and splenic artery after lymph node dissection. White arrows, splenic artery; black arrow, common hepatic artery; gray arrow, celiac artery; white arrow head, stump of the splenic artery; black arrow head, stump of the left gastric artery

insertion and darning of the anvil of a conventional circular stapling device (PCEEA, USSC). In the proximal gastrectomy cases, the distal transection of the stomach on a suitable resection line, found by referring to the intragastric clips placed to confirm the location of the tumor in preoperative gastroendoscopy, was performed through a wound in the right lower quadrant (HALS wound) extracorporeally (Fig. 3). Then, jejunogastrostomy and jejunojejunostomy in the interposition cases, and jejunojejunostomy (Y-anastomosis) in the total gastrectomy cases, were carried out extracorporeally with a conventional hand-sewn technique thorough the HALS wound. The esophageal anastomoses (esophagojejunostomy in the total gastrectomy and the interposition cases, and esophagogastrostomy in the proximal D1 cases) were performed intracorporeally by PCEEA after enlarging the $12-\mathrm{mm}$ port adjacent to the navel to 3 or $4 \mathrm{~cm}$ in order to insert the body of the PCEEA into the peritoneal cavity. The reconstruction of the digestive tract was completed by closure of the jejunal or gastric stump through which the body of the PCEEA had been inserted with a laparoscopic linear stapling device (endo-GIA, USSC) (Fig. 4). Laparoscopic images after jejunogastrostomy and jejunojejunostomy of the jejunal interposition are shown 


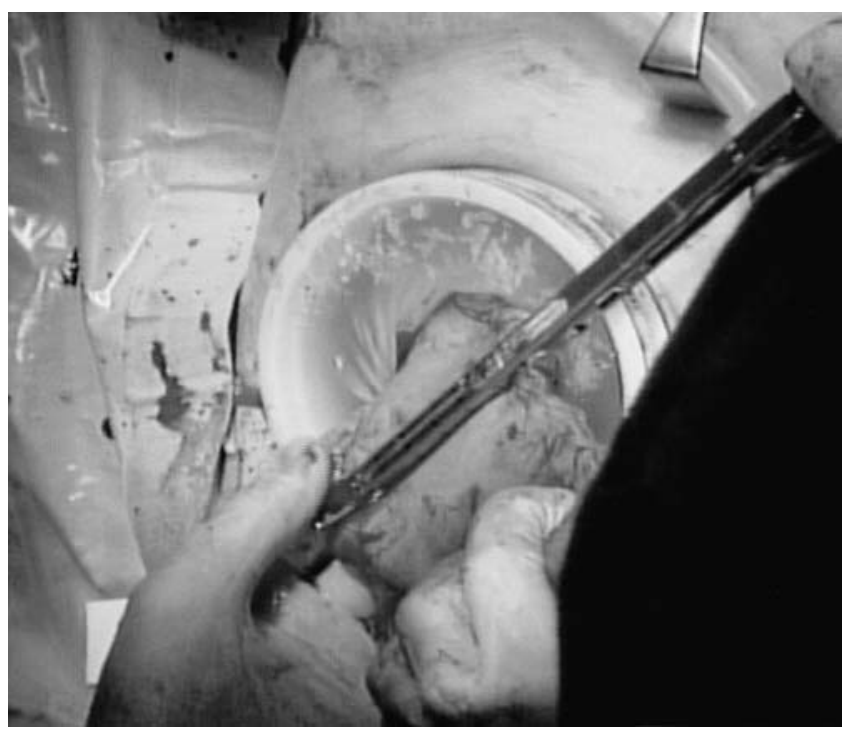

Fig. 3. Distal transection of the stomach through the HALS wound

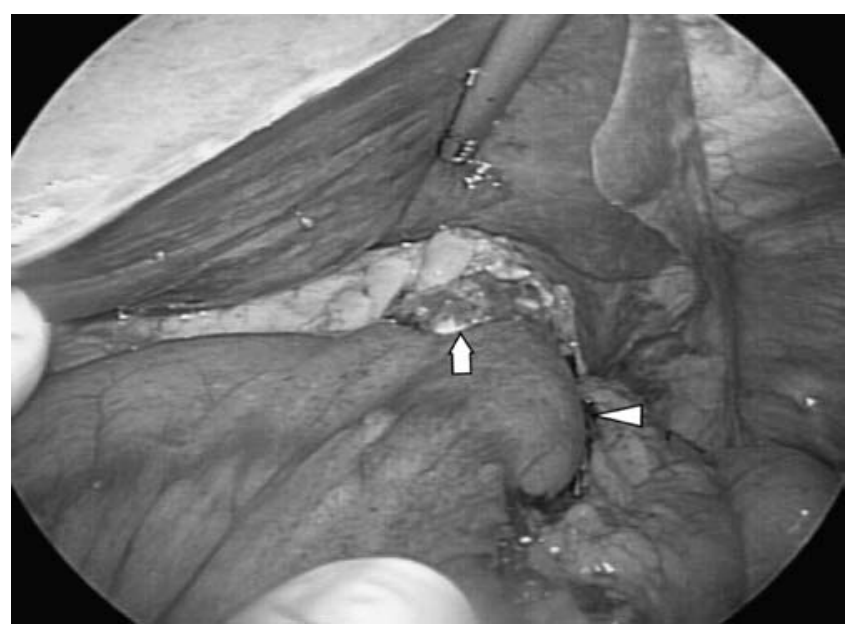

Fig. 4. Laparoscopic image after esophagojejunostomy. Arrow, suture line of esophagojejunostomy; arrow head, stump of jejunum

in Figs. 5 and 6, respectively. A view of the postoperative wound is shown in Fig. 7.

\section{Results}

The average duration of the operation was $266 \mathrm{~min}$ (range 195-340 $\mathrm{min}$ ) in the total gastrectomy group and $237 \mathrm{~min}$ (range 160-315 min) in the proximal gastrectomy group, and the average amount of blood loss was $178 \mathrm{ml}$ (range $40-550 \mathrm{ml}$ ) in the total gastrectomy group and $173 \mathrm{ml}$ (range $20-320 \mathrm{ml}$ ) in the proximal gastrectomy group. These are considered to be reasonably satisfactory results. The depth of tumor invasion was

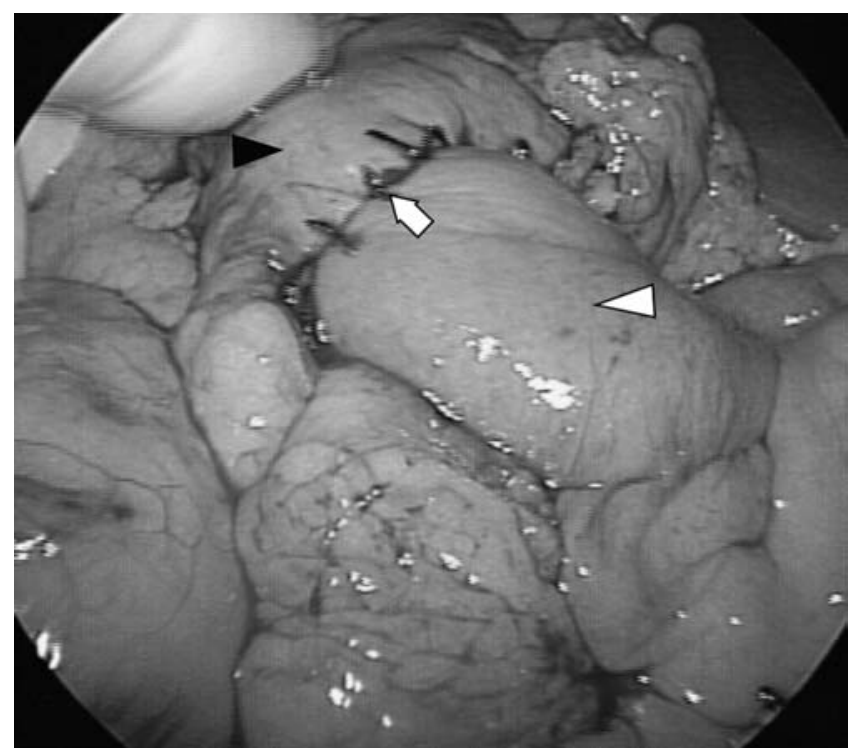

Fig. 5. Laparoscopic image after jejunogastrostomy of the jejunal interposition. Arrow, suture line of jejunogastrostomy; white arrow head, interposed jejunum; black arrow head, remnant of stomach

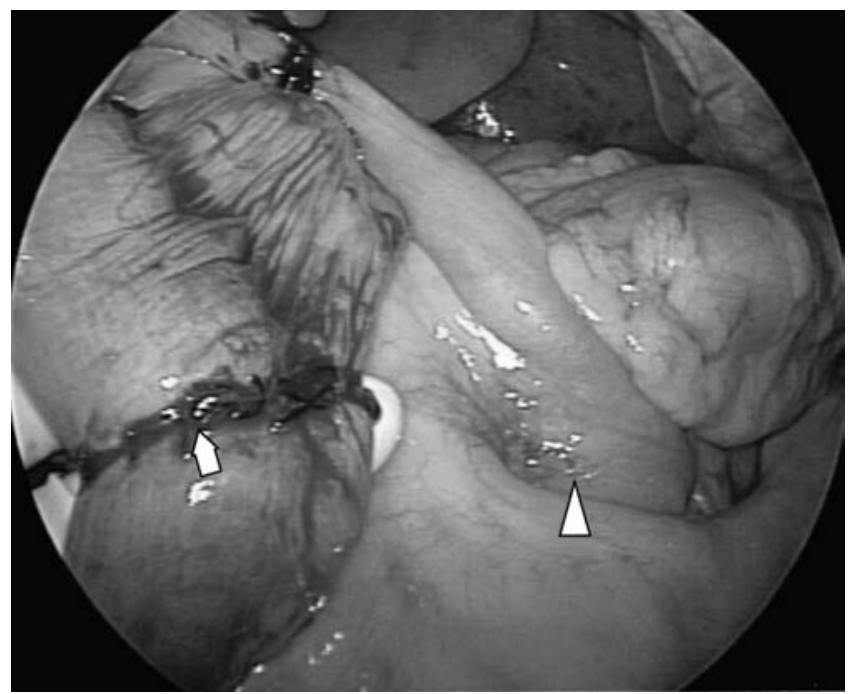

Fig. 6. Laparoscopic image after jejunojejunostomy of the jejunal interposition. Arrow, suture line of jejunojejunostomy; arrow head, Treutz' ligament

diagnosed postoperatively as mucosal in 5 cases, submucosal-sm 1 in 2 cases, submucosal-sm 2 in 6 cases and proper muscular in 3 cases in the total gastrectomy group, and mucosal in 2 cases, submucosal-sm 1 in 8 cases (D1-esophagogastrostomy group), submucosal$\mathrm{sm} 2$ in 1 case, and proper muscular in 1 case (D2interposition group) in the proximal gastrectomy group. The histological types were papillary adenocarcinoma in 3 cases, well differentiated in 1 case, moderately differentiated in 4 cases, and poorly differentiated in 8 
Table 2. Laparoscopic gastrectomy for upper gastric cancer

\begin{tabular}{|c|c|c|}
\hline & Total gastrectomy $(n=16)$ & Proximal gastrectomy $(n=12)$ \\
\hline Male/female & $11 / 5$ & $7 / 5$ \\
\hline Age (years, mean \pm SD) & $61.4 \pm 11.8$ & $67.6 \pm 9.2$ \\
\hline Duration of operation (min, mean $\pm \mathrm{SD}$ ) & $266 \pm 43$ & $237 \pm 45$ \\
\hline Blood loss $(\mathrm{ml}$, mean $\pm \mathrm{SD})$ & $178 \pm 145$ & $173 \pm 112$ \\
\hline No. of dissected lymph nodes (mean \pm SD) & $38 \pm 10$ & $27 \pm 10$ \\
\hline \multicolumn{3}{|l|}{ Histological type } \\
\hline Papillary & 3 & 0 \\
\hline Well differentiated & 1 & 6 \\
\hline Moderately differentiated & 4 & 3 \\
\hline Poorly differentiated & 8 & 3 \\
\hline \multicolumn{3}{|l|}{ Depth of tumor invasion } \\
\hline Mucosa & 5 & 2 \\
\hline Submucosa(sm1) & 2 & $8^{\mathrm{a}}$ \\
\hline Submucosa(sm2) & 6 & $1^{\mathrm{b}}$ \\
\hline Proper muscular layer & 3 & $1^{\mathrm{b}}$ \\
\hline \multicolumn{3}{|l|}{ Lymph node metastases } \\
\hline Negative & 14 & 10 \\
\hline Positive $^{c}$ & 2 & $2^{\mathrm{b}}$ \\
\hline Walking (days, mean \pm SD) & $1.2 \pm 0.4$ & $1.1 \pm 0.3$ \\
\hline Flatus (days, mean $\pm \mathrm{SD}$ ) & $3.0 \pm 0.7$ & $3.2 \pm 0.8$ \\
\hline Oral feeding (days, mean \pm SD) & $6.1 \pm 1.2$ & $4.8 \pm 0.6$ \\
\hline Discharge (days, mean $\pm \mathrm{SD}$ ) & $18.2 \pm 3.7$ & $13.1 \pm 1.4$ \\
\hline
\end{tabular}

a D1-esophagogastrostomy group

${ }^{\mathrm{b}} \mathrm{D} 2$-interposition group

${ }^{\mathrm{c}}$ Metastases to group 1 lymph nodes

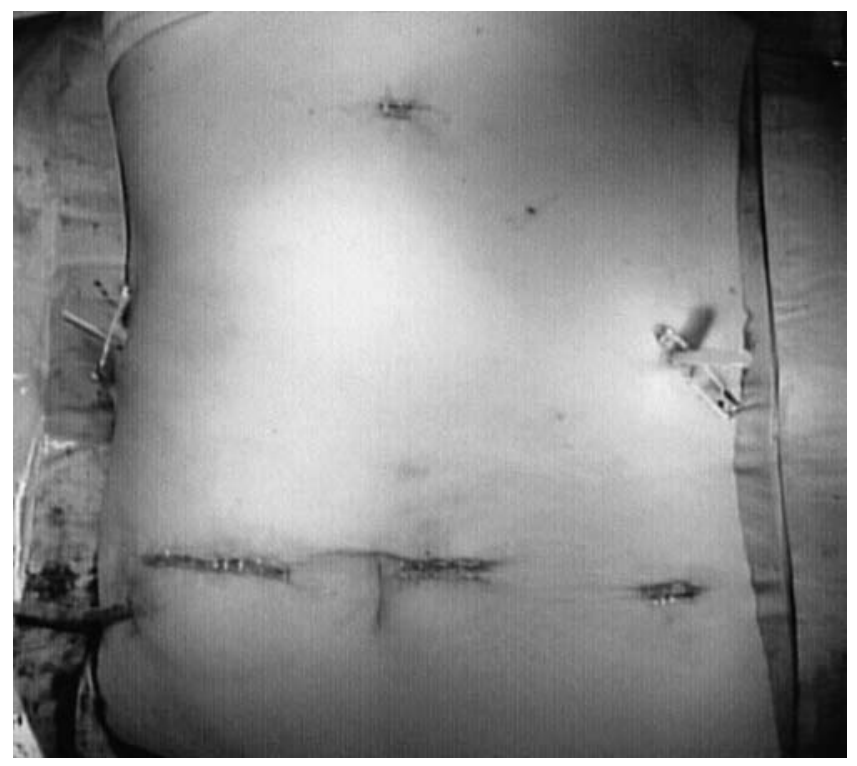

Fig. 7. View of postoperative wound

cases in the total gastrectomy group, and well differentiated in 6 cases, moderately differentiated in 3 cases, and poorly differentiated in 3 cases in the proximal gastrectomy group. Metastases to the group 1 lymph nodes were seen in 4 cases ( 2 in the total gastrectomy group and 2 in the proximal interposition group), and the average number of dissected lymph nodes per patient was 38 (range 22-57) in the total gastrectomy group and 27 (range 9-48) in the proximal gastrectomy group.

Postoperative complications resulted in a minor leakage of pancreatic juice in one patient in the total gastrectomy group, and this was treated conservatively, whereas trouble from anastomosis did not occur. The postoperative periods of walking, flatus, oral feeding, and discharge were 1.2 days (range 1-2 days), 3.0 days (range 2-4 days), 6.1 days (range 5-8 days), and 18.2 days (range 13-23 days), respectively, in the total gastrectomy group, and 1.1 days (range 1-2 days), 3.2 days (range 2-4 days), 4.8 days (range 3-5 days) and 13.1 days (range 11-16 days), respectively, in the proximal gastrectomy group (Table 2). These periods were all inclined to be shorter than those for the conventional open gastrectomy group $(n=30)$, among whom the periods of walking, flatus, oral feeding, and discharge were 2.0 days, 3.9 days, 7.8 days, and 24.5 days, respectively. Although the postoperative periods of observation are relatively short, no recurrence has occurred in these 28 patients.

\section{Discussion}

Recently, laparoscopy-assisted distal gastrectomies have been performed for early gastric cancer [4,5]. 
However, in these procedures, the ablation of the stomach and lymph node dissection were carried out laparoscopically, and then a minilaparotomy on the upper abdomen was used for additional lymph node dissection and anastomosis. Moreover, the degrees of lymph node dissection were often only within group $1+$ no. 7 and 8 a lymph nodes, and so their indications have been limited to mucosal cancers. We used a minilaparotomy for HALS at the beginning of the operation to carry out gastrectomy with groups 1 and 2 lymph node dissection as efficiently as is done with a conventional open gastrectomy. There are few reports of a laparoscopic operation for upper gastric cancer [6]. With our procedure, we could perform lymph node dissection and reconstruction in a shorter time and more easily than with the complete laparoscopic procedure.

HALS has been used for operations such as splenectomy, colectomy, partial gastrectomy, etc. [7-9]. It is thought to be better to insert a hand into the peritoneal cavity from the lower abdomen, slightly away from the epigastric operating field, because manipulation becomes easier. In addition, this technique is better from a cosmetic point of view, and there is a reduction in postoperative wound pain compared with an epigastric skin incision, which is necessary after gastrectomy and lymph node dissection for extracorporeal reconstruction $[4,5]$.

\section{Conclusions}

In summary, laparoscopic gastrectomy with regional lymph node dissection by HALS for upper gastric can- cer is thought to be less invasive than conventional open gastrectomy, and yet just as safe. Moreover, it can be performed in a shorter time and more easily than the completely closed procedure. The intracorporeal anastomosis using PCEEA is also considered to be a safe and sure procedure after laparoscopic total or proximal gastrectomy.

\section{References}

1. Tanimura S, Higashino M, Fukunaga Y, Kato H. Laparoscopic distal gastrectomy with D2 lymphadenectomy for gastric cancer (in Japanese). J Jpn Soc Endosc Surg 2000;5:134-9.

2. Tanimura S, Higashino M, Fukunaga Y, Osugi H. Hand-assisted laparoscopic distal gastrectomy with regional lymph node dissection for gastric cancer. Surg Laprosc Endosc Percut 2001;11:15560.

3. Japanese Gastric Cancer Association. Japanese classification of gastric carcinoma. 13th ed. Tokyo: Kanehara; 1999.

4. Nagai Y, Tanimura H, Takifuji K, Kashiwagi H, Yamoto H, Nakatani Y. Laparoscope-assisted Billroth I gastrectomy. Surg Laparosc Endosc 1995;5:281-7.

5. Kitano S, Shimoda K, Miyahara M, Shiraishi N, Bandoh T, Yoshida $\mathrm{T}$, et al. Laparoscopic approach in the management of patients with early gastric carcinomas. Surg Laparosc Endosc 1995;5:359-62.

6. Uyama I, Sugioka A, Fujita J, Komori Y, Matsui H, Hasumi A. Laparoscopic total gastrectomy with distal pancreatosplenectomy and D2 lymphadenectomy for advanced gastric cancer. Gastric Cancer 1999;2:230-4.

7. Kusminsky RE, Boland JP, Tiley EH, Deluca JA. Hand-assisted laparoscopic splenectomy. Surg Laparosc Endosc 1995;5:463-7.

8. O'Reilly MJ, Saye WB, Mullins SG, Pinto SE, Falkner PT. Technique of hand-assisted laparoscopic surgery. J Laparoendosc Surg 1996;6:239-44.

9. Watson DI, Game PA. Hand-assisted laparoscope vertical banded gastroplasty. Initial report. Surg Endosc 1997;11:1218-20. 